\title{
Informed consent di Instalasi Gawat Darurat RSUP Prof. Dr. R. D. Kandou Manado
}

\author{
${ }^{1}$ Christilia G. Wagiu, ${ }^{2}$ Erwin G. Kristanto, ${ }^{3}$ Theo Lumunon \\ ${ }^{1}$ Program Studi Ilmu Kesehatan Masyarakat Pascasarjana Universitas Sam Ratulangi \\ Manado \\ ${ }^{2}$ Fakultas Kedokteran Universitas Sam Ratulangi Manado \\ ${ }^{3}$ Fakultas Hukum Universitas Sam Ratulangi Manado \\ Email: christilia.wagiu@gmail.com
}

\begin{abstract}
According to the Minister of Health regulation No. 290 Year 2008 article 1 which is relevant to medical intervention issues, informed consent has to be signed by the patient prior to any medical intervention after the patient has been informed completely about the purpose and the risk of certain intervention. In general, medical doctors already admits that informed consent is an important part of the ethical code of their profession. Albeit, in certain circumstances such as in emergency cases with life or physical handicap threatening, the medical doctors are demanded to do medical intervention 'ignoring' the informed consent. This study was aimed to obtain the implementation of informed consent in Emergency Care Unit at Prof. Dr. R. D. Kandou Hospital Manado, the central referral hospital in East Indonesia. In this study, we used qualitative method through interview, direct field observation, and document observation as secondary data. The results showed that informed consent was implemented at the Emergencey Care Unit, however, in emergency cases, informed consent was given orally, followed by signing it as soon as the intervention had been completely performed. Conclusion: Informed consent was implemented in every medical intervention at Prof. Dr. R. D. Kandou Hospital including the Emergency Care Unit.
\end{abstract}

Keywords: informed consent, emergency care unit

\begin{abstract}
Abstrak: Menurut ketentuan Permenkes No. 290 tahun 2008 pasal 1 yang mengatur tentang tindakan medik disebutkan bahwa ijin melakukan tindakan medik diberi oleh pasien setelah terlebih dahulu pasien mendapat penjelasan tentang tujuan dan manfaat maupun risiko dari tindakan medik tersebut. Umumnya dokter telah mengetahui dan mengakui bahwa persetujuan tindakan medik atau informed consent ialah bagian kode etik profesi sebelum diatur dalam ketentuan undang-undang tentang rumah sakit, praktik kedokteran, maupun peraturan menteri kesehatan. Dalam keadaan tertentu dokter juga dituntut untuk dapat segera melaksanakan tindakan medis dan mengesampingkan informed consent antara lain dalam keadaan gawat darurat dimana terdapat ancaman kematian atau kecacatan. Penelitian ini bertujuan untuk mengetahui penyelenggaran persetujuan tindakan medik di Instalasi Gawat Darurat RSUP Prof. Dr. R. D. Kandou yang merupakan rumah sakit pusat rujukan di Indonesia Timur. Pada penelitian ini digunakan metode kualitatif melalui wawancara, pengamatan langsung di lapangan, dan observasi dokumen sebagai data sekunder. Hasil penelitian mendapatkan bahwa informed consent di Instalasi Gawat Darurat masih tetap dipakai, walaupun pada keadaan gawat darurat persetujuan diberikan secara lisan baru setelah selesai tindakan baru dimintakan tanda tangan pada lembar informed consent. Simpulan: Informed consent tetap diperlukan untuk setiap tindakan kedokteran yang dilakukan di RSUP Prof. Dr. R. D. Kandou termasuk pada Instalasi Gawat Darurat.
\end{abstract}

Kata kunci: informed consent, emergency unit care 
Setiap pasien memiliki keunikan, kebutuhan, kekuatan, dan kepercayaan masing-masing. Rumah sakit membangun kepercayaan dan komunikasi terbuka dengan pasien untuk memahami dan melindungi psikososial serta nilai spiritual setiap pasien. Hasil pelayanan akan bertambah baik bila mereka yang berhak mengambil keputusan diikut sertakan dalam keputusan pelayanan dan proses yang sesuai harapan. ${ }^{1}$

Pelaksanaan medis antara dokter dan pasien merupakan hubungan atas dasar kepercayaan (trust). Hubungan antara dokter dan pasien pada dasarnya bertumpu pada dua macam hak dasar yang sifatnya individual, yaitu hak atas informasi (the right to information) dan hak untuk menentukan nasib sendiri (the right of self determination). ${ }^{2}$ Ketentuan UndangUndang Dasar 1945, mengenai hak untuk menentukan nasibnya sendiri, diatur dalam Pasal 28 A yaitu bahwa setiap orang berhak untuk hidup serta berhak mempertahankan hidup dan kehidupannya, sedangkan ketentuan mengenai hak atas informasi diatur pada pasal $28 \mathrm{~F}$ yaitu bahwa setiap orang berhak untuk berkomunikasi dan memperoleh informasi untuk mengembangkan pribadi dan lingkungan sosialnya, serta berhak untuk mencari, memperoleh, memiliki, menyimpan, mengolah, dan menyampaikan informasi dengan menggunakan segala jenis saluran yang tersedia. ${ }^{3}$

Dalam pasal 1 ayat 1 Peraturan Menteri Kesehatan No. 290 Tahun 2008 tentang persertujuan tindakan kedokteran dikatakan bahwa persetujuan tindakan kedokteran atau informed consent adalah persetujuan yang diberikan oleh pasien atau keluarga terdekat setelah mendapatkan penjelasan secara lengkap mengenai tindakan kedokteran. ${ }^{4}$ Di dunia kedokteran informed consent tidak asing lagi. Setiap tenaga medis meskipun tidak memahami informed consent sebagai suatu prosedur hukum namun sudah mengetahuinya sebagai sebuah kewajiban moral etika kedokteran. Seorang penulis bahkan menuliskan bahwa jauh sebelum adanya ketentuan hukum di dunia yang mengatur tentang informed consent, moral dan etika seorang dokter untuk meminta ijin terlebih dahulu sebelum melakukannya tindakan mediknya telah tertanam jauh melalui pendidikan etika profesinya sebagaimana diajarkan oleh Hipocrates. ${ }^{5}$

Terdapat banyak tindakan dan pelayanan medik yang dilakukan dokter atau tenaga medis lainnya yang berpotensi merupakan malpraktik yang dilaporkan masyarakat tapi tidak diselesaikan secara hukum. ${ }^{6}$ Tercapainya kesepakatan antara dokter dan pasien merupakan dasar dari seluruh proses tentang informed consent. ${ }^{7}$ Untuk itulah sebaiknya persetujuan diberikan oleh keluarga atau pasien setelah diberikan penjelasan oleh dokter yang akan melakukan tindakan.

RSUP Prof. Dr. R. D. Kandou merupakan rumah sakit pusat rujukan Indonesia Timur sehingga tingkat kunjungan pasien menjadi sangat tinggi. Menurut data resmi RSUP Prof. Dr. R. D. Kandou tahun 2015, jumlah pasien di Instalasi Gawat Darurat (IGD) sebanyak 36.920 atau sebanyak 102 pasien setiap harinya sehinggai penerapan informed consent sangat diperlukan di IGD. Sampai saat ini dipercaya bahwa keadaan gawat dan darurat pasien sudah merupakan syarat tidak diperlukan informed consent. Berdasarkan asumsi medik maupun hukum, situasi gawat dan darurat menimbulkan kewajiban hukum bagi yang terkait dalam hal rumah sakit maupun dokter untuk memberikan pertolongan terutama dalam rangka menyelamatkan jiwa seseorang yang sedang terancam. Kewajiban moral dan ikatan dari etika profesi untuk menyelamatkan setiap jiwa mengharuskan dan sebenarnya memberikan alasan bagi seorang dokter/rumah sakit untuk bertindak tanpa informed consent. ${ }^{8}$ Persoalan teoritis inilah yang menjadi penelitian ini sangat relevan untuk dikaji pelaksanaan informed consent di Instalasi gawat darurat.

\section{METODE PENELITIAN}

Penelitian ini menggunakan metode kualitatif. Data primer diperoleh melalui wawancara langsung dengan panduan 
wawancara yang dipilih berdasarkan pada prinsip kesesuaian dan kecukupan, ditunjang dengan pengamatan langsung di lapangan dan didukung dengan observasi dokumen sebagai data sekunder. Data diolah dan dianalisis dengan metode analisis isi yaitu melakukan interpretasi induksi. Hasil wawancara dibuatkan transkrip, setelah dilakukan interpretasi terhadap setiap pertanyaan dan jawaban. Hasil intepretasi dilakukan verifikasi untuk melihat apakah hasil intepretasi tadi itu sejalan dengan konteks pertanyaan yang diajukan kemudian dilakukan pembersihan dan perumusan konsep. Setiap konsep tadi dijadikan sub bahasan. Validasi data dilakukan dengan cara triangulasi sumber dan triangulasi metode.

\section{HASIL PENELITIAN DAN BAHASAN}

Pada Permenkes No. 290 Tahun 2008 pasal 4 ayat (1) mengatakan bahwa dalam keadaan gawat darurat, untuk menyelamatkan jiwa pasien dan/atau mencegah kecacatan tidak diperlukan tindakan kedokteran, namun di Instalasi Gawat Darurat RSUP Prof. Dr. R.D. Kandou Manado informed consent tetap ada. Pada saat pasien datang ke Instalasi Gawat Darurat dokter triase akan menilai apakah pasien ini termasuk true emergency atau false emergency, bila pasien dalam keadaan true emergency atau bisa dikatan membutuhkan tindakan segera maka persetujuan dimintakan secara lisan terlebih dahulu, baru setelah selesai tindakan dokter akan memintakan tanda tangan pada lembar informed consent. Penelitian ini sesuai dengan penelitian yang dilakukan oleh Ardani di Madiun, ${ }^{9}$ yang menyimpul-kan bahwa pada setiap tindakan medis seorang dokter wajib melaksanakan informed cosent terlebih dahulu, namun dalam keadaan gawat darurat dimana terdapat ancaman kematian atau kecacatan bisa dilakukan tindakan terlebih dahulu.

Pada pelaksanaannya, penjelasan yang diberikan dokter sesuai dengan Permenkes No. 290 Tahun 2008 yaitu mencakup diagnosis dan tata cara tindakan kedokteran, tujuan tindakan kedokteran yang dilakukan, alternatif tindakan lain dan risikonya, risiko dan komplikasi yang mungkin terjadi, prognosis terhadap tindakan yang dilakukan, sedangkan perkiraan pembiayaan hanya ada pada general consent. Penjelasan yang diberikan menggunakan bahasa Indonesia dan bahasa lokal agar mudah dimengerti oleh pasien maupun keluarga. Penjelasan diberikan oleh dokter kepada pasien Sesuai dengan Undang-Undang Dasar 1945 Pasal 28 F, bahwa setiap orang berhak untuk berkomunikasi dan memperoleh informasi untuk mengembangkan pribadi dan lingkungan sosialnya, serta berhak untuk mencari, memperoleh, memiliki, menyimpan, mengolah, dan menyampaikan informasi dengan menggunakan segala jenis saluran yang tersedia. Penelitian yang dilakuan oleh Winterbottom et al. ${ }^{10}$ juga mendukung, bahwa pasien menganggap proses informed consent merupakan proses komunikasi dokter dan pasien, bahkan mendidik pasien akan risiko atas tindakan yang akan dilakukan.

Penjelasan diberikan kepada pasien tanpa ada paksaan untuk menyetujui tindakan yang akan dilakukan, sesuai dengan Undang-Undang Dasar 1945 Pasal 28 A bahwa setiap orang berhak untuk hidup serta berhak mempertahankan hidup dan kehidupannya. Hal ini sejalan dengan penelitian yang dilakukan oleh Perihan et $\mathrm{al}^{11}$ di Turki, yaitu pasien memiliki hak otonomi untuk menentukan tindakan yang dapat dilakukan terhadap dirinya. Pada pengamatan dan hasil wawancara, seringkali dokter hanya sendiri dalam memberi penjelasan tentang tindakan yang akan dilakukan, tidak didampingi oleh perawat atau tenaga medis lainnya sebagai saksi. Pada pengawasan, terdapat petugas pengawas di Instalasi Gawat Darurat yang akan memeriksa apakah lembar informed consent telah terisi lengkap. Pada kasus pasien yang akan dioperasi, pengawas akan memeriksa terlebih dahulu apakah sudah ada persetujuan untuk dilakukan operasi atau belum. Bila belum ada persetujuan dari pasien atau keluarga untuk dilakukan operasi, maka pengawas tidak akan 
mengijinkan untuk dilaksanakan operasi tersebut, namun pada pengamatan langsung didapatkan sekitar 6 lembar informed consent yang tidak lengkap terisi.

\section{SIMPULAN}

Penyelenggaraan informed consent di RSUP Prof. Dr. R. D. Kandou Manado tetap diperlukan untuk setiap tindakan kedokteran yang dilakukan termasuk di Instalasi Gawat Darurat. Pada tindakan medik yang masih memungkinkan waktu dan keadaan seperti tindakan invasif, informed consent diberikan sebelum tindakan dilakukan, namun dalam situasi yang benar-benar darurat seperti resusitasi maka dokter meminta persetujuan pada keluarga secara lisan kemudian setelah dilakukan tindakan resusitasi baru dimintakan tanda tangan keluarga pada lembar informed consent.

Pelaksanaan informed consent sesuai dengan Permenkes No. 290 Tahun 2008 sudah berjalan dengan baik walaupun masih terdapat kekurangan, yaitu terkadang dokter memberi penjelasan tanpa didampingi tenaga medis lain sebagai saksi, dan pada pengawasan, petugas masih kurang teliti karena didapatkan 6 lembar informed consent yang tidak lengkap terisi.

\section{SARAN}

1. Dokter harus memberikan informasi sejelas-jelasnya sesuai Peraturan Menteri Kesehatan No. 290 Tahun 2008 kepada pasien dan memastikan bahwa informasi tersebut telah dipahami seluruhnya, baik pada tindakan medis yang memerlukan informed consent maupun tindakan medis yang tidak memerlukan informed consent. Dokter juga harus bisa menjelaskan alasan mengapa tindakan medis yang dilakukan tidak memerlukan informed consent, sehingga tidak terjadi persepsi hak pasien telah dilalaikan.

2. Pasien dan keluarga harus selalu berperan aktif dalam proses perawatan dan pelaksanaan informed consent demi memperlancar pelaksanaan tindakan medis terhadap pasien itu sendiri.

3. Pada pelaksanaannya, diperlukan pengawasaan yang lebih baik lagi agar lembar informed consent benar-benar bisa terisi lengkap dan agar selalu didampingi saksi saat menjelaskan tindakan yang akan dilakukan.

\section{DAFTAR PUSTAKA}

1. Standar Akreditasi Rumah Sakit. Jakarta: Kementerian Kesehatan RI, 2012.

2. Winandayu P. Tanggung Jawab Dokter terhadap Pasien Gawat Darurat atas Tindakan Medis Berdasarkan Implied Consent (Studi Kasus di Rumah Sakit Panti Nugroho Yogyakarta) [Tesis]. Yogyakarta: UAJY, 2013.

3. Undang-Undang Dasar 1945 Pasal 28 tentang Hak Asasi Manusia. Jakarta, 1945.

4. Keputusan Menteri Kesehatan Mentri Kesehatan Republik Indonesia Nomor 290/Menkes/ PER/III/2008 tentang Persetujuan Tindakan Kedokteran. Jakarta: Depkes RI, 2008.

5. Tambun GJ. Hukum Kesehatan Kedokteran dan Rumah Sakit. Manado: Pacific Institute, 2016.

6. Erdiansyah. Pertanggungjawaban pidana terhadap dokter atas kesalahan dan kelalaian dalam memberikan pelayanan medis di Rumah Sakit. Jurnal Ilmu Hukum. 2011;3(2) p.296-320

7. Hanafiah MJ, Amir A. Etika Kedokteran dan Hukum Kesehatan. Jakarta: EGC, 2012.

8. Manual Persetujuan Tindakan Kedokteran. Jakarta: Konsil Kedokteran Indonesia, 2006.

9. Ardani RY. Pertanggung jwaban perdata dokter mengenai tindakan medis tanpa informed consent [Skripsi]. Jakarta: Fakultas Hukum Universitas Indonesia; 2014.

10. Winterbottom M, Boon H, Mior S, Facey M. Informed consent for chiropractic care: comparing patients perceptions to the legal perspective. Manual Ther. 2015;20(3):463-8.

11. Ekmekci PE, Ekmecki AB, Karakas O, Kulduk A, Arda B. Evaluation of the informed consent procedure for total knee arthroplasty patients in Turkey. Acta Orthopaedica et Traumatologica Turcica. 2016;50:400-4. 